\title{
ИННОВАЦИОННАЯ БЕЗОПАСНОСТЬ И КЛАСТЕРИЗАЦИЯ В ДИНАМИКЕ МУЛЬТИЦИКЛИЧЕСКОГО РЕГИОНАЛЬНОГО ВОСПРОИЗВОДСТВА: ДЕКОМПОЗИЦИЯ, МОДЕЛЬ, СПЕЦИФИКА ПРИГРАНИЧНЫХ РЕГИОНОВ
}

\author{
(c) 2019 Горочная Василиса Валерьевна \\ кандидат экономических наук, специалист по учебно-методической работе \\ Южный федеральный университет, Россия, Ростов-на-Дону \\ научный сотрудник \\ Балтийский федеральный университет им. И. Канта, Россия, Калининград \\ E-mail: tunduk@hotmail.com
}

\begin{abstract}
Автор статьи осуществляет структурно-понятийную декомпозицию категории инновационной безопасности приграничного региона, позволившую выявить основные её проблемные аспекты в современном дискурсе. Проводится концептуализация региональной кластерной самоорганизации как многосторонней реакции деловой среды региона на внешние и внутренние угрозы инновационной безопасности. На основе концепта взаимозависимой осцилляции воспроизводственного цикла составлена структурно-логическая и экономико-математическая модель взаимовлияния регионального кластерогенеза и инновационной безопасности. Теоретические положения и выводы верифицированы на эмпирическом материале по западным приграничным регионам России.
\end{abstract}

Ключевые слова: инновационная безопасность региона, кластеры, циклическая динамика, региональное воспроизводство, самоорганизация.

Введение. Как практика изучения, так и система управления инновационным развитием и безопасностью в современной России нуждается в обновлении и на уровне инструментально-методологического аппарата, и на уровне концептуализации базовых категорий, самого сложившегося понимания инновационной безопасности региона и её составляющих. Данное обстоятельство вызвано ведущим значением инновационной составляющей в глобальной экономической и технологической конкуренции, в которую активно включается как национальное хозяйство в целом, так и регионы. Вопросы инновационной безопасности регионов активно разрабатываются в российской науке, прежде всего, в качестве составного компонента экономической безопасности в целом (с преемственной методикой исследования и оценки) [2], [5], [12], [14], [20], [27], [29], [30]. Наряду с данным понятием в научной практике закрепились такие категории, как «эффективность использования инновационного потенциала региона» [22], а также «управление использованием факторов инновационного роста» [26]. Усиливающаяся «гуманизация» понимания экономической безопасности, активное включение в него социокультурного компонента, а также учёт качества человеческого капитала как важного фактора обеспечения безопасности [6] в настоящее время активно проецируется и на научное осмысление инновационной безопасности, в том числе - как качественной характеристики инновационной и деловой среды региона [19], инновационной культуры [14]; установлена её взаимозависимость с качеством жизни населения [13].

Всё больше осознаётся необходимость изучения процессов инновационного роста и обеспечения инновационной подсистемы экономики в свете внутренних закономерностей динамики регионального воспроизводства. Обнаруживаются конкурентное (связанное с необходимостью синхронизации с глобальными и макрорегиональными циклами технологического обновления), а также циклическое (происходящее из внутренней логики самоорганизующегося развития деловой среды региона) измерения экономической безопасности [6], что относится в полной мере и к её инновационной составляющей. Ещё Дж. Китчином [32] была выявлена устойчиво идентифицируемая осцилляция с длиной волны в 2-4 года, связанная с ростом и рецессией, ведомыми в первую очередь процессами смены технологических поколений. В настоящее время вопросы экономического и инновационного развития рассматриваются в тесной связи с циклами различной природы: 
общеэкономическим и технологическим, проявляющим себя наиболее ярко в конкретных отраслях [18], инвестиционным [21], информационным (в том числе информационно-инновационным, а также динамикой кодифицированного и тацитного знания) [3], [4], [7], социальным [1], управленческим [17], в том числе с учётом рисков и экстерналий форсированного инновационного развития и цифровизации для социокультурной среды и системы управления [16]. Особого внимания заслуживает и циклическая динамика кластерной самоорганизации деловой среды региона [8], [9], представляющая большую значимость для интеграции усилий региональной инновационной среды в условиях импортозамещения в приграничных регионах, где «критическая масса» предприятий формируется всем трансграничным пространством [11], [23], [28], [31]. В текущей ситуации, тем самым, внутренние риски инновационной безопасности усугубляются негативной внешней ситуацией [24], в том числе вызванной турбулентной динамикой, так же имеющей собственные циклические закономерности и логику осцилляторного развёртывания [6], [10]. В связи с этим применение заявленной М. Портером категории экономического кластеpa [33], а также производное понятие инновационного кластера, имеют важное значение в свете проблем инновационной безопасности как для изучения и отслеживания динамики организационной среды региона, так и в качестве маркера способности региональной экономической системы к проявлению самоорганизующейся реакции на внешние и внутренние вызовы и угрозы безопасности.

В настоящем исследовании проведём теоретическую концептуализацию категории инновационной безопасности приграничного региона с теоретико-методологических позиций изучения сложных открытых систем с нелинейной динамикой развития в рамках теории хаоса, а также с использованием метода структурно-понятийной декомпозиции, что позволит выявить основные проблемные аспекты в сложившемся теоретическом осмыслении инновационной безопасности приграничного региона в современном дискурсе и административной практике. Поскольку цель данной работы состоит в выявлении принципов и порядка взаимодействия инновационной безопасности приграничного региона с мультицикличностью регионального воспроизводства, будут применены методы структурно-логического (в том числе сценарного) и экономико-математического моделирования с учётом концепции цикла кластерной самоорганизации [9], геоэкономической турбулентности [10] и информационного подхода к изучению системной эмерджентности [15], а при эмпирической верификации результатов - комплекс статистических методов, основанных на анализе динамических рядов.

Структурно-понятийная декомпозиция понятия «инновационная безопасность региона». Сложившиеся подходы к изучению, мониторингу, управлению инновационной безопасностью на национальном и региональном уровне во многом производны от самого круга понятий, выстраивающихся на основе сложившихся представлений о диалектике взаимодействия внутренней и внешней среды как потенциальных и реальных источников угроз, а также внутренней управляемой системы обеспечения защиты. Если провести структурную декомпозицию понятия «инновационная безопасность приграничного региона», то обнаруживается не только проблема разнопорядковости и неоднозначности категории «инновация» в современной российской научной и управленческой практике (в том числе откладывающая отпечаток на систему статистического учёта инноваций, во многих случаях не дающей чёткой и достоверной картины: не каждое изобретение или новая технология является инновацией и соответствует требованиям целесообразности и рыночной рентабельности), но и ряд проблем понимания центральной категории «безопасность». Оно выстраивается по дихотомическим осям «безопасность - опасность», «безопасность - риск», «безопасность (как гарантия долгосрочного существования) - неопределённость», «безопасность - угроза». При этом если категория неопределённости чаще всего не подвергается внутренней структурной аналитике (хотя природа происхождения неопределённости и ситуативность её проявления заслуживают развёрнутого исследования и классификации: например, неопределённость как следствие волатильности или турбулентности имеют существенные отличия [10]), то угрозы традиционно подразделяются на внутренние и внешние, а структура рисков классифицируется по факторам их возникновения. Обеспечение безопасности понимается по принципам «угроза - защита», в том числе предполагается возможность системного и про- 
граммного обеспечения защиты (см. Рис. 1).

Важным аспектом осмысления безопасности является дихотомия «текущее, казуально обусловленное состояние - относительно постоянное, воспроизводимое собственной динамикой свойство». Последнее означает не столько наличие либо отсутствие угроз, сколько готовность к перманентному преодолению рискогенных факторов, к адаптации через самоорганизацию и развитую предикацию (отчасти также к их переосмыслению и использованию с извлечением положительного эффекта для регионального воспроизводства). Учитывая уже упомянутую усиливающуюся за последние годы гуманизацию понятия безопасности в социально-экономическом дискурсе [6], включение в её смысло- вое поле соответствия ценностям и приоритетам регионального сообщества и его элиты (любой фактор рассматривается в качестве угрозы, будучи идентифицированным, осознанным в качестве такового), как структура рисков, так и дихотомия «внешние - внутренние угрозы» могут быть подвергнуты серьёзному пересмотру, так как любой фактор риска (в том числе осознаваемый как внешний) формируется при существенном влиянии внутренних причин.

Особое значение дихотомия «внешнее - внутреннее» обретает в случае приграничных регионов. Категория границы в современном научном дискурсе воспринимается в единстве её контактных и барьерных свойств [28], [31]. Внешние экономические и научно-технологические кон-

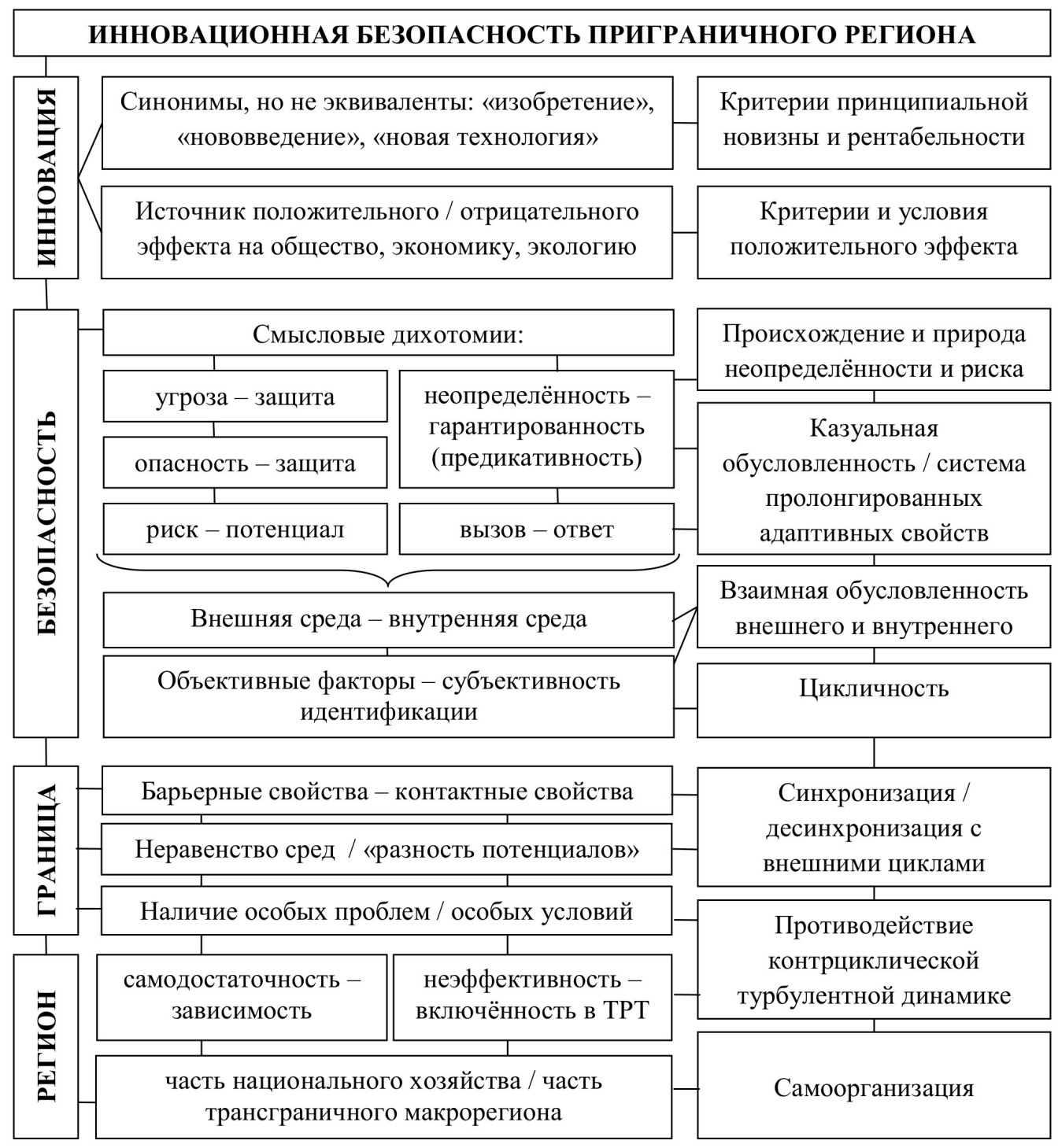

Puc. 1. Схема структурной декомпозиции понятия «инновационная безопасность приграничного региона» (разработано автором) 
такты несут в себе 2 основные группы проблем: сложности взаимодействия в условиях различия национальных социально-экономических систем, деловых культур и правовых режимов, а также риски утраты партнёрства с иностранными контрагентами по причинам, выходящим за пределы собственно социально-экономической рациональности контракции и лежащие в плоскости геополитики и вызываемых ею геоэкономических турбулентных явлений.

В первом случае как барьерность, так и контактность границы играют свою роль: потоками товаров и услуг, кадров и информации движет именно «разность потенциалов», задаваемая неравномерностью их распределения и сравнительной стоимостью по обе стороны границы. В то же время, таковые потоки (и в особенности потоки информации и технологий, приводящие к диффузии инноваций) являются действенными в условиях хорошей инфраструктурной и социокультурной «проходимости» среды. Тем самым инновационная безопасность как свойство означает стремление к наиболее эффективному использованию конкурентных преимуществ территории и поддержание относительной эквивалентности её инфраструктурного развития, человеческого капитала и деловой среды для обеспечения синхронизации с циклами глобального обновления.

Во втором случае включённость приграничного региона в территориальное разделение труда вызывает специфический круг проблем обеспечения его безопасности, выстраивающийся вокруг дихотомий «открытость - закрытость», «самодостаточность как гарантия внешней независимости - риски упущенных возможностей эффективного использования сравнительных преимуществ от международной торговли и кооперации» [6]. При этом имеет значение и трактовка категории «регион» как части национальной социально-экономической, правовой и управленческой системы либо как части трансграничного образования более крупной таксономической единицы (что в российских условиях западных наиболее значимо для регионов Северо-Запада, активно включённых в пространство балтийского трансграничного региона, что сказывается, в свою очередь, и на их экономической ритмике, деловой и научно-образовательной среде [23]).

Обобщая все перечисленные проблемные стороны, инновационную безопасность региона (и в особенности приграничного региона, за- висимого от внешней среды) можно определить не как состояние стабильности, защищённости инновационной сферы региона от внутренних и внешних угроз, а как комплекс резистентных свойств, позволяющих всем субъектам инновационного воспроизводства (в том числе управленческой и бизнес-элите, а также региональному социуму в целом):

- сбалансированно и поступательно избирать текущие и стратегические приоритеты инновационного развития региона, в условиях неопределённости и риска осуществлять парето-эффективное принятие решений;

- своевременно производить идентификацию (в том числе прогностическую) возникающих вызовов инновационному воспроизводству;

- осуществлять своевременное предотвращение, преодоление и минимизацию рискогенных факторов за счёт достижения когерентности самоорганизующихся рыночных, управленческих, научно-технологических и информационных, процессов, а также динамики социокультурной среды и человеческого капитала, определяющих связность последовательных стадий циклической динамики инновационного воспроизводства и их способность к поддержанию системного целого в постоянно меняющихся условиях;

- поддерживать здоровый двусторонний информационный, технологический, кадровый и экономический обмен с мировым сообществом и в особенности с сопредельными территориями (в том числе поддержание «проходимости каналов» и использование конкурентных преимуществ территории), а также обеспечивать возможности его оперативной компенсации при утрате деловых контактов с сохранением рыночной рентабельности и конкурентоспособности.

Мультициклическая обусловленность инновационного роста. Для выявления условий обеспечения инновационной безопасности и развития региона составим идеальную модель самоорганизации и саморегуляции циклических компонент регионального воспроизводства. На основе выделенных в рамках сформированного концепта составляющих примем в оборот 4 основных цикла: информационно-инновационный, организационный, собственно экономический (коммерческий), а также циклическую динамику человеческого капитала (как 
на социокультурном, так и на кадровом уровне). В соответствии с моделью самоорганизации региональной социально-экономической системы [9], выделим три основных стадии цикла:

1. инициальный сдвиг начальных условий, приводящий систему в неравновесное состояние, меняющий её аттрактор и тем самым запускающий самоорганизующиеся процессы;

2. фаза активного роста, мультипликации ключевых динамических параметров системы в результате действия нелинейных механизмов;

3. фаза сокращения после достижения пределов роста, когда происходит запуск ограничивающих факторов вследствие обратных нелинейных зависимостей, что приводит к ито- говому становлению осцилляции системы, обретающей циклический аттрактор.

Отобразим динамику циклов регионального воспроизводства, выстроив их в последовательности по МСРВ (максимальной скорости распространения взаимодействия): от наиболее быстрых информационных процессов через более инертные организационные и кадровые - к коммерческим, сопряжённым с наибольшими рисками и лаговыми эффектами (см. Рис. 2)

Как видно из схемы, первая стадия каждого из циклов оказывается определяющей для наступления третьей фазы в последующем цикле в приведённой последовательности. Так, осознанная обществом потребность в инновациях, а так-
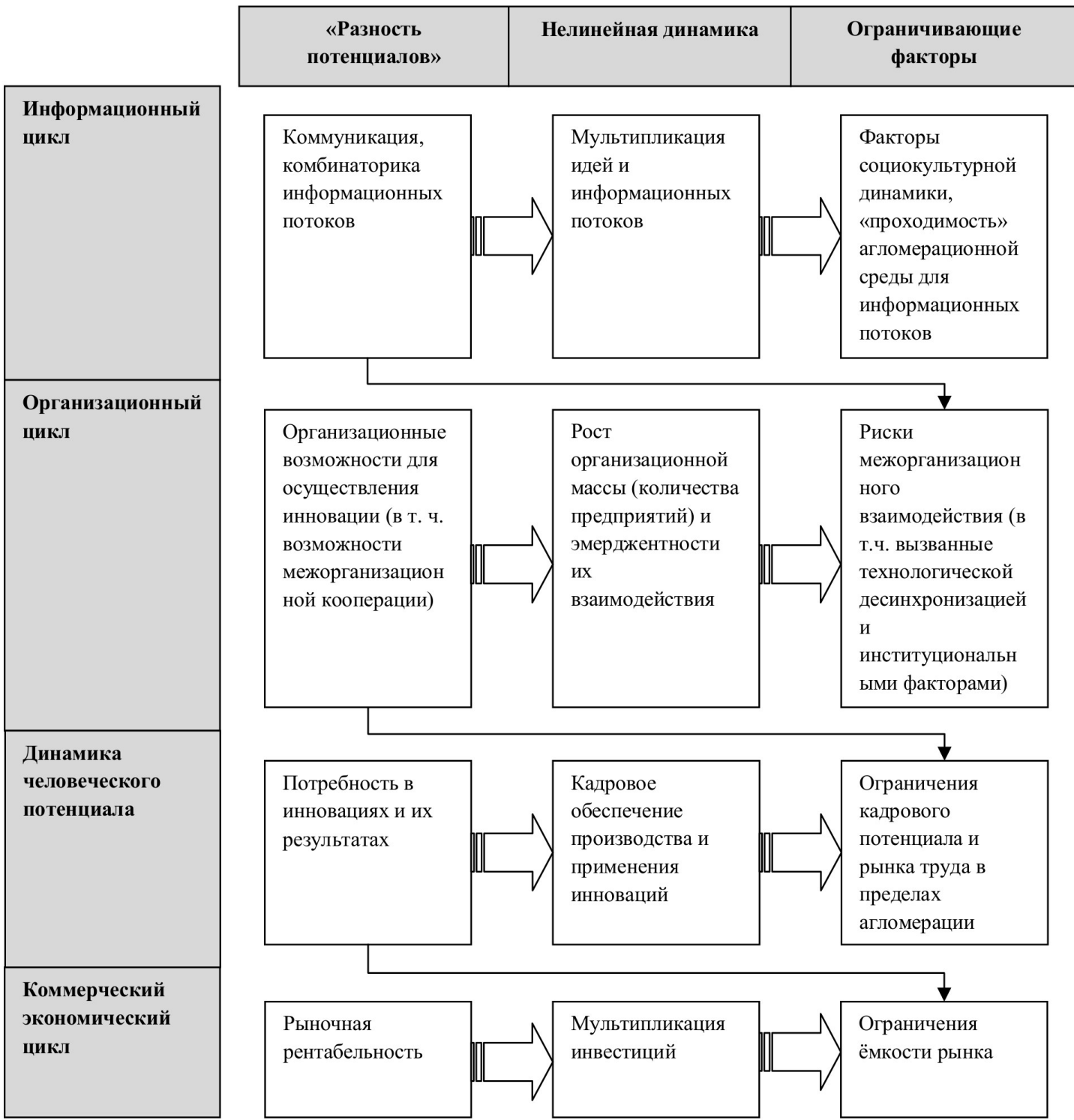

Puc. 2. Схема развёртывания трёх стадий самоорганизующихся циклов регионального воспроизводства (разработано автором) 
же доверие к ним и готовность их использовать служат по масштабу своего проявления ограничителями ёмкости рынка инноваций; организационные возможности (в том числе количество и масштаб инновационно активных предприятий) являются ограничителями для рынка труда и самореализации высоко квалифицированного кадрового потенциала; динамика информационных потоков, исходная информационная плотность и проходимость среды (как в плане явного кодифицированного знания, так и в плане неявного тацитного) задаёт ограничения для межорганизационного (и в особенности - кластерного) взаимодействия предприятий [7], поскольку от данных параметров зависят уровень доверия между ними и взаимная синхронизация технологических обновлений (особенно важная для комплиментарных производств, а также последовательных звеньев единой цепи добавленной стоимости).

В связи с выявленными зависимостями становится очевидной положительная роль инновационных региональных кластеров, поскольку в них естественным образом на основе самоорганизующихся процессов достигается взаимная синхронизация информационного обмена кодифицированным (явным) знанием на фоне кумулятивного накопления пласта тацитного (неявного) знания, динамики организационной среды и кадрового потенциала, что в итоге положительно отразится на коммерческих результатах. В случае разрозненных предприятий и звеньев ЦДС возможности активного развития в рамках одного цикла могут «натолкнуться» на отсутствие потенциала для роста в рамках других, либо напротив - вместо естественных ограничений произойдёт гипертрофированный рост, приводящий к диспропорциям и экстерналиям инновационного роста (пусть такой сценарий и существенно более редко реализуется на практике). Таким образом, кластерная самоорганизация и саморегуляция достигаются благодаря мультициклической синхронизации в случае достаточной организационной массы, лояльности и доверия между предприятиями, координации их усилий, а также эмерджентности, возникающей благодаря эффекту масштаба и экономии от совместного пользования объектами инфраструктуры.

Следует учитывать, что как процесс, чувствительный к начальным условиям, самоорганизация всегда зависит от инициальных им- пульсов и сложившейся последовательности взаимодействия фаз мультициклической осцилляции. Итогом сценарного структурно-логического моделирования стала последовательность их взаимного наложения, характеризующаяся наибольшими возможностями саморегуляции и самоподдержания (см. Рис. 3).

Наряду с закономерностью, обозначившейся в предыдущей схеме, при данном порядке мультициклического наложения обнаруживается «полный круг» саморегуляции системы (графически обозначенный на Рис. 3 последовательностью внешней окружности). Расширение ёмкости рынка, происходящее за счёт расширения общественной потребности и интереса, приводит к мультипликации идей, так как одна инновация может найти поливариантное рыночное применение, стать основой для дальнейших разработок. В свою очередь, данный фактор способствует повышению возможностей для развития организационной среды (вокруг новообразованных проектов с большей вероятностью могут возникнуть соответствующие поддерживающие их организационные структуры: лаборатории, центры развития, новые предприятия, а также филиалы и структурные подразделения уже существующих фирм). Возможности для развития корпоративного сектора снижают ограничения на рынке труда, создаются дополнительные рабочие места, а в среднесрочной и долгосрочной перспективе происходит мультипликация произведённых инвестиций. Повышение интенсивности деловых процессов, совместные инвестиции и технологические разработки усиливают интенсивность коммуникации и информационного обмена между предприятиями, происходит накопление совместного тацитного знания, что, в свою очередь снижает трансакционные издержки и контракционные риски и тем самым снимает многие ограничения по межорганизационному взаимодействию. В том числе, вступает в силу обмен кадрами, повышение их квалификации и опыта, создаются реальные основания для соответствующего кадрового обеспечения процессов разработки, внедрения и продуктивного использования инноваций в профессиональной деятельности, что повышает рентабельность инноваций, расширяя рынок и сферу их потребления, а также снимает часть ограничений по социокультурным рискам их недоброкачественного применения в производстве и массовом потреблении населением. 


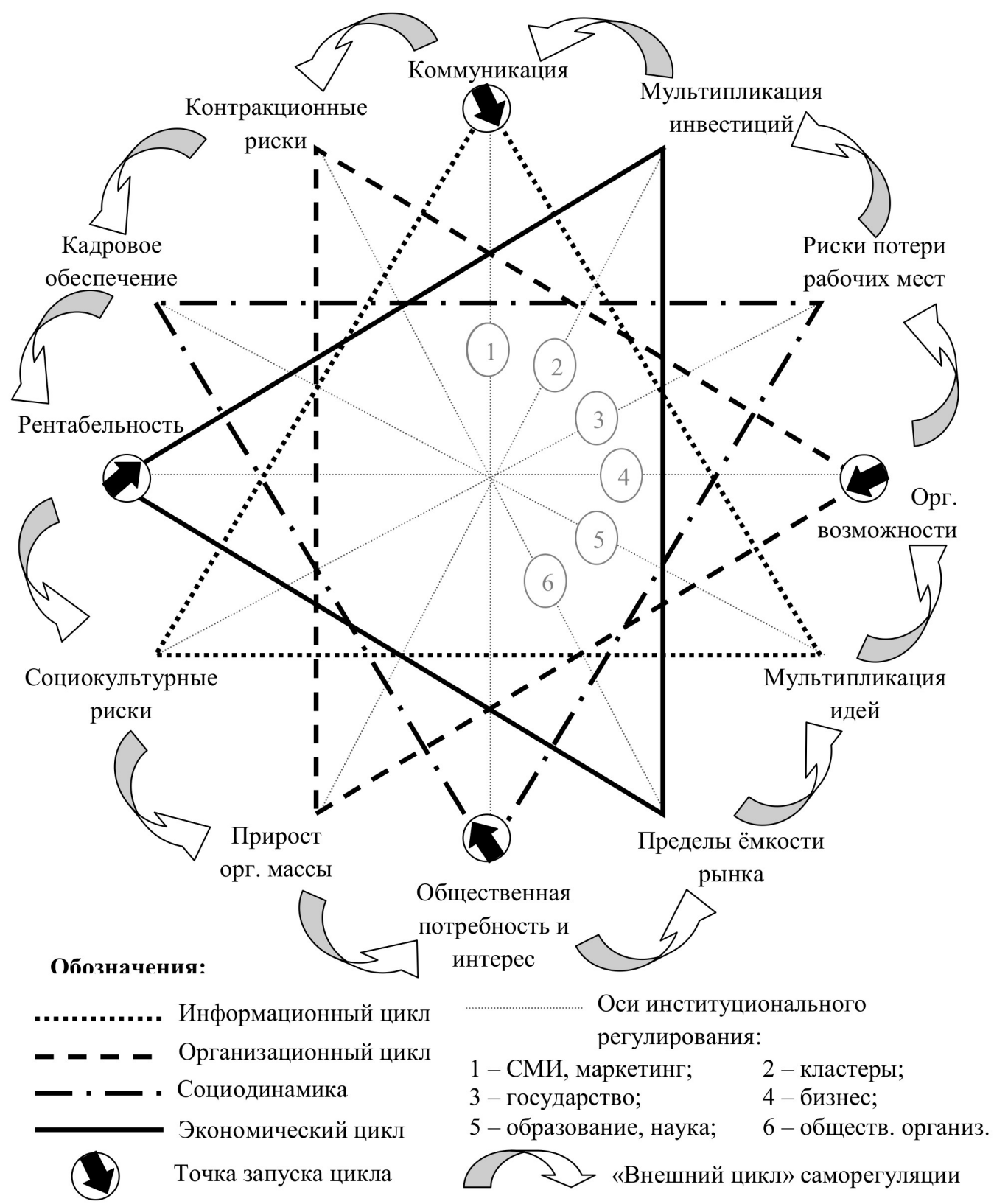

Puc. 3. Схема мультициклической самоорганизации и саморегуляции инновационного воспроизводства региона (разработано автором)

Итогом пройденного цикла для корпоративного сектора является необходимый для кластерообразования прирост организационной массы, для населения с несколько большим лаговым эффектом - новая волна осознанной потребности и интереса к инновациям.

Однако вся описанная последовательность действует лишь в случае её соблюдения и внутренней синхронизации стадий. Соответственно, задача такой синхронизации должна специально решаться через естественные координирующие механизмы, как внутренние, так и внешние. В свою очередь, их действие обладает собственной внутренней связностью. На основе выделенного сценария обнаруживается не только внешний саморегулятивный цикл, но и «распределение ролей» в институциональной регуляции стадий цикла, выстроенное по шести «осям симметрии». Две из них объединяют инициальные фазы циклов (на Рис. 3 обозначенные как №1 и №4), ещё две - отвечают за синхронность стадий мультипликативного роста (на Рис. 3 соответственно №2 и №5), также две - за наличие естественных ограничений (на Рис. 3 со- 
ответственно №3 и №6).

Инициальные стадии информационного цикла и социодинамики оказываются на одной оси, их регуляция происходит через институт СМИ и маркетинговых структур: общественный и деловой интерес к инновациям формируется через коммуникативный процесс. Сдвиг начальных условий в рыночной рентабельности вместе с организационными возможностями реализации проекта осознаётся непосредственно бизнесом.

Проблемы на рынке труда, а также ограничения и риски, связанные с экстерналиями использования инноваций для общества, экономики, экологии и культуры, равно как и страхование и снижение рисков контракции и недостаточной ёмкости рынка инноваций - находятся в прямых интересах и ведении государственных и общественных структур. Они осуществляют публичный контроль и создают гарантии для населения и бизнеса.

Особую значимость в цикле самоорганизации представляет стадия нелинейных механизмов мультипликации и роста. Именно её наступление означает жизнеспособность образующихся структур и процессов, их самоподдерживающуюся природу [9]. Поэтому начальные условия, задающие дальнейший тренд развития самоорганизующихся экономических явлений, определяются не только инициальным импульсом, но именно первыми двумя фазами цикла в их неразрывном единстве, в противном случае импульс не находит своего продолжения и затухает, а образующиеся структуры нуждаются во внешней поддержке [9]. Мультипликация инвестиций синхронизируется с приростом организационной «критической массы» благодаря формированию и деятельности экономических кластеров, а мультипликация идей и возможностей применения технологий синхронизируется с ростом компетентности кадрового потенциала и широких слоёв населения как итоговых потребителей инноваций через систему науки и образования. Соответственно, именно деятельность кластерных (и аналогичных им объединений организационной и инновационной среды региона) и научно-образовательных структур оказывается определяющей для общей жизнеспособности процессов генерации, коммерциализации и адсорбции инноваций.

В случае приграничного региона относительно мультициклической динамики инновацион- ного роста имеют место три группы факторов, откладывающих отпечаток на инновационное воспроизводство:

1. Необходимость синхронизации с внешними циклами, либо устойчивая и сильная корреляционная зависимость от них, которая может как синхронизовывать, так и десинхронизовывать внутрирегиональный цикл. При наличии внутренних ограничений, темповых и циклических несоответствий по отдельным звеньям цикла чаще всего происходит недоиспользование потенциала других звеньев, либо реже - их гипертрофированное проявление и итоговая разбалансировка цикла (например, регион становится преимущественно потребителем инноваций и их ретранслятором вглубь страны при слабой их внутренней генерации).

2. Необходимость оперативного возмещения звеньев цикла, «выпадающих» вследствие утраты критической массы зарубежных контрагентов и научно-технологических партнёров.

3. Необходимость противостояния геоэкономической турбулентной динамике [10], контрциклической по отношению к региональному инновационному воспроизводству, в особенности для коммерческого (экономического) и организационного циклов, наиболее чувствительных по отношению к нему.

Во всех трёх случаях требуется целостное, комплексное усиление регионального цикла инновационного воспроизводства, а также наиболее чувствительных его звеньев (как в силу самого характера влияния внешних факторов, так и в силу фазовой суперпозиции в момент начала и активного развёртывания последствий негативных внешнеэкономических явлений). В этом свете образование инновационных экономических (а также, в качестве сопутствующего элемента - образовательных) кластеров позволяет одновременно решить сразу несколько задач и достичь синергии за счёт сплочения внутрирегиональной среды. Их формализация в количественных величинах с учётом прямых и обратных зависимостей может быть произведена (соответственно наиболее чувствительным переменным экономики приграничного региона) следующим образом:

- по оси, непосредственно относящейся к кластерному уровню организации регионального хозяйства (№2 на Рис. 3), - частичная либо полная компенсация (К) потери «критической массы» контрагентов (М) и объёма контрак- 
ции (произведение среднего объёма единичной сделки $\mathrm{AQ}$ на количество взаимодействий между предприятиями Е), а также отрицательного мультипликатора (m) за счёт сокращения инвестиционных потоков (I) и сопутствующей утраты эффекта масштаба, дающего экономию средних производственных издержек (AC) и покрытие производственных рисков (R) за счёт собственных средств предприятий:

$K_{M}=(\Delta M \cdot A Q \cdot E-\Delta A C)(1-\Delta R), A C=f(M, E, Q, \phi),(1)$

$K_{I}=\Delta I \cdot m \cdot(1-\Delta R), I=f(M, E, Q)$,

(разработано автором на основе: [9])

- по оси бизнеса (№4 на Рис. 3) - компенсация снижения рентабельности инновационной деятельности (r), с учётом коэффициента дисконтирования залога (h) и организационных возможностей за счёт эмерджентности взаимодействия предприятий $(\phi)$ :

$$
\begin{aligned}
& K_{r}=\Delta I \cdot h \cdot \sum_{t=o}^{T}(1+\Delta r)^{-1}, r=f(M, E, Q, D), \\
& K_{\phi}=\frac{\log _{2}(M+E)}{\log _{2} M}, E=f(r, R, L),
\end{aligned}
$$

(разработано автором на основе: [9], [15])

- по оси, регулируемой общественными структурами и отчасти государством (№6 на Рис. 3) - компенсация сужения объёмов спроса (D) при утрате внешних рынков сбыта (в том числе производимая за счёт переориентации на внутренний рынок, создание внутрикластерного спроса по звеньям ЦДС, а при сотрудничестве кластеров с государством - через привлечение госзаказа), а также возрастающих трансакционных издержек и посреднических расходов при сохранении зарубежных контактов $\left(\mathrm{C}_{\mathrm{TrF}}\right)$ при снижении внутрикластерных $\left(\mathrm{C}_{\mathrm{TrCl}}\right)$, рисков исполнения обязательств (R) и снижения уровня межорганизационного доверия (L), с учётом, что таковая тенденция, зарождаясь в пространстве трансграничного взаимодействия, может распространяться и вглубь регионального делового пространства:

$$
\begin{aligned}
& K_{D}=\Delta D \cdot A Q, D=f(M, E, L, R), \\
& K_{C T r}=\frac{\phi \cdot \Delta L \cdot \Delta C_{T r C l}}{\Delta C_{T r F}}(1-\Delta R), C_{T r C l}=f(M, E) . \\
& \quad(\text { разработано автором) }
\end{aligned}
$$

Объединяя все полученные выражения (16), с учётом указанных побочных функциональных зависимостей, отражающих региональную специфику, составим модель общего компенсационного эффекта кластерной самоорганизации в условиях разрушения либо искажения регионального инновационного воспроизводственного цикла:

$$
\begin{aligned}
& K_{G}=\frac{\log _{2}(M+E) \cdot \Delta L \cdot \Delta C_{\text {TrCl }}}{\log _{2} M \cdot \Delta C_{T r F}} \\
& \cdot\left(\Delta M \cdot \Delta D \cdot A Q-\Delta A C+\Delta I \cdot h \cdot \sum_{t=o}^{T}(1+\Delta r)^{-1}\right) \cdot(1-\Delta R) . \\
& \quad(\text { разработано автором) }
\end{aligned}
$$

Цикличность инновационного воспроизводства и кластеризация в западных приграничных и приморских регионах России. При наличии целого ряда показателей инновационной динамики регионов (в том числе характеризующих отдельные стадии данного процесса) в основу анализа данного исследования будет положен один из центральных индикаторов, характеризующий итоговую коммерциализацию инноваций - долю инновационного продукта в общем годовом объёме товаров и услуг (с глубиной архива данных до 2000 г. включительно, что позволяет отследить характер циклических явлений в относительно протяжённой ретроспективе, а также выявить характер реакции на негативные внешнеэкономические проявления после 2014 г.).

С целью выявления специфики западных приграничных регионов в целом произведём сравнение тренда среднего по данной категории субъектов значения показателя с общероссийским (см. Рис. 4).

На фоне относительно более высоких значений показателя по России в целом, для западных приграничных регионов частота осцилляции выше: длина волны порядка 2 лет, а в целом по России она достигает 4-5 лет. Общероссийский рост 2010-2013 гг., вызванный ставкой на развитие инноваций на уровне федеральной политики, практически не сказался на западных приграничных регионах, однако на них (в направлении роста) сказалась внешняя ситуация после 2014 г., способствовавшая консолидации местных производителей инновационного продукта. В разрезе по регионам также обнаруживается своя специфика. Так, наибольший рост показали юго-западные регионы (см. Рис. 5). 


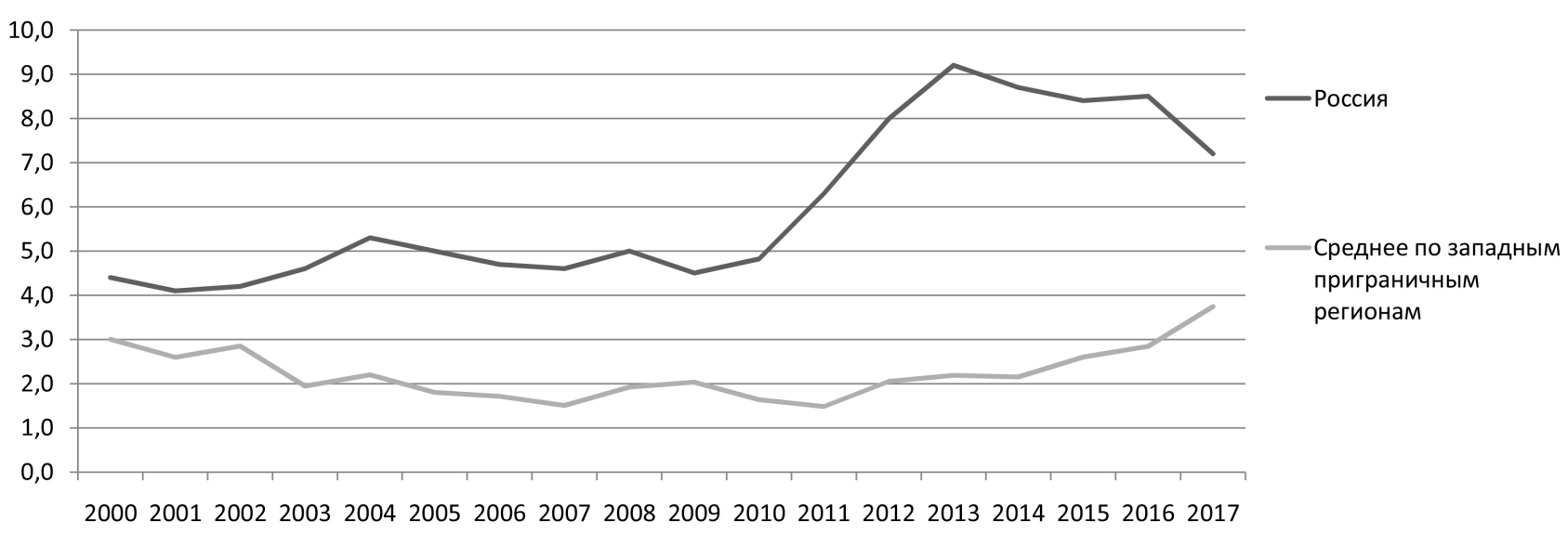

Puc. 4. Динамика общероссийского и среднего по западным приграничным регионам показателя доли инновационного продукта, \% (составлено автором на основе: [25])

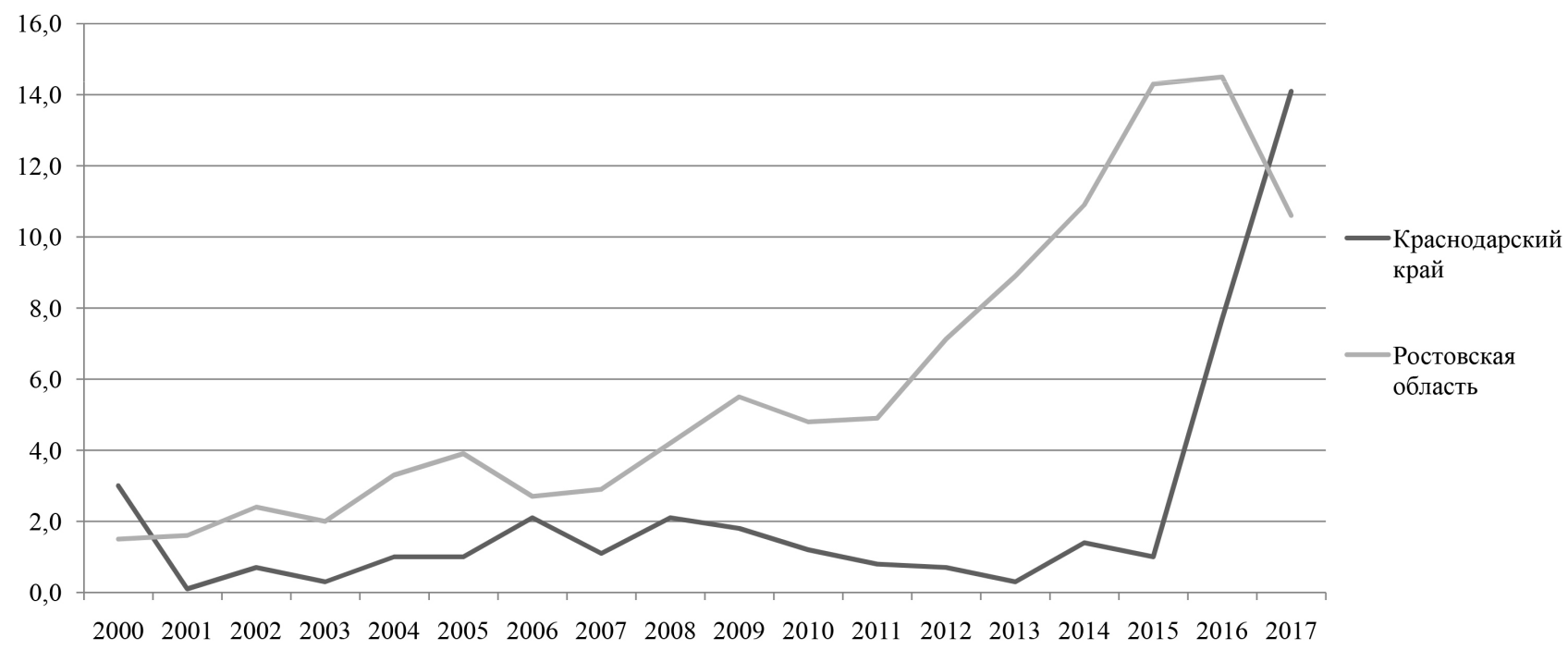

Puc. 5. Динамика доли инновационного продукта в Ростовской области и Краснодарском крае, \% (составлено автором на основе: [25])

Для Краснодарского края логика сохранявшегося на протяжении длительного времени двухлетнего цикла была нарушена как длительным спадом до 2013 г., так и сменившим его активным ростом после масштабных государственных инвестиций в туристический сектор, способствовавших дальнейшему мультипликативному эффекту, в том числе в смежных отраслях. В настоящее время благодаря данному мощному импульсу происходит кардинальная перестройка ритмики развития инновационного сектора региона, становление нового цикла. Динамика инновационного роста Ростовской области с годовым лаговым интервалом практически повторяет общероссийский контур, при этом за весь рассматриваемый период очевидно постепенное расширение цикла от 2 до 4 лет.

Более амплитудной динамика цикла на протяжении всего рассматриваемого периода является в Воронежской и Белгородской областях, так же постепенно расширяющих цикл от 2-х до 3-4-х летнего (см. Рис. 6).

Более сглаженная динамика Курской области, напротив, от 5-6-ти летнего цикла перешла к 2-3 летнему. При этом на всех трёх регионах сказалась общероссийская тенденция к росту после 2010 г., а на Воронежской области, на протяжении длительного времени наиболее тесно связанной научно-технологическими контактами с экономикой сопредельной Украины, негативно 


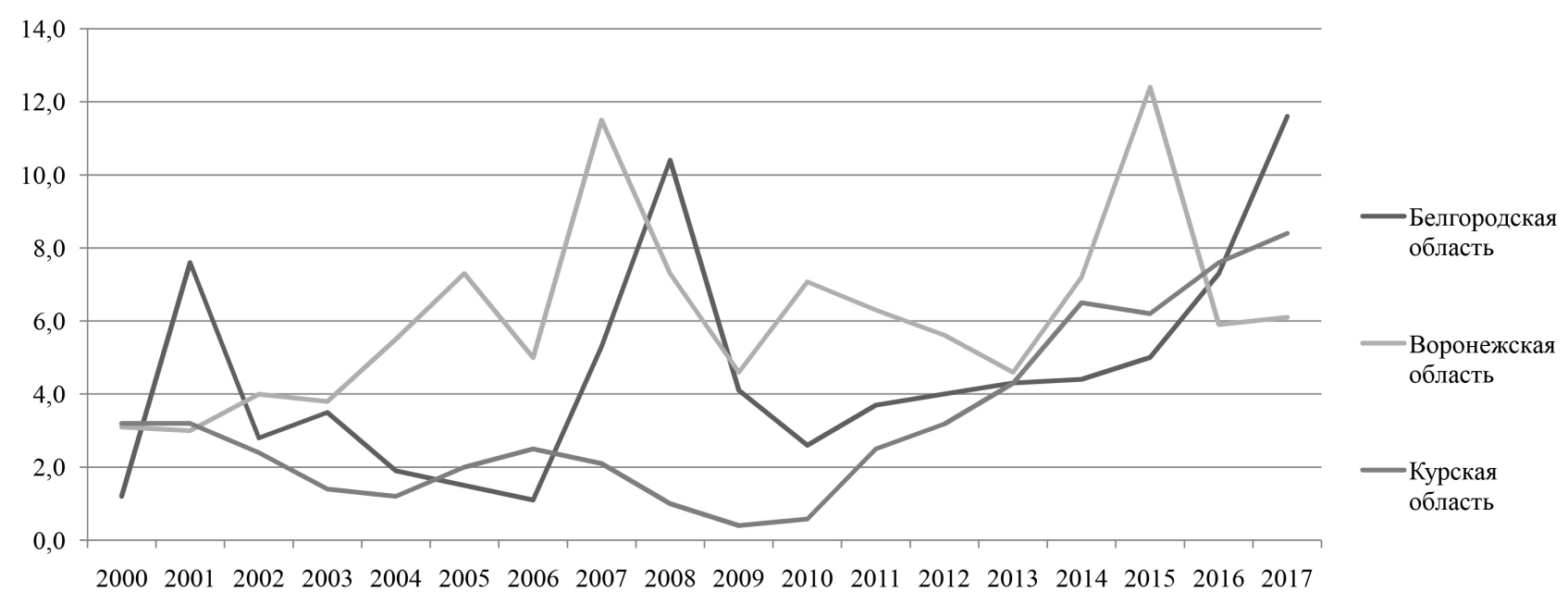

Puc. 6. Динамика доли инновационного продукта в Воронежской, Белгородской и Курской областях, \% (составлено автором на основе: [25])

отразились внешние изменения после 2014 г.

Брянская область демонстрирует амплитудную, но устойчивую (с 3-4 летней длиной волны) осцилляцию. В Смоленской области, как и в большинстве регионов, длина цикла расширяется, достигая от 2 до 5 лет, увеличивая амплитуду и демонстрируя повышенные темпы в кризисных ситуациях 2009 и 2014 г., что может свидетельствовать об активизации и самоорганизующейся интеграции деловой среды (см. Рис. 7).

Вызывает опасения динамика Псковской области: при относительно «сглаженном» и расширяющемся по продолжительности цикле регион не демонстрирует ни собственного инновационного роста, ни откликается на общероссийскую положительную динамику. Доля инновационной продукции продолжает оставаться на кри- тически низком уровне (редко превышая 2\%) и не обнаруживает каких-либо ощутимых тенденций к росту на протяжении более 10 лет.

Также ситуацию небезопасности в инновационной сфере можно идентифицировать в Калининградской области. В целом, северо-западные приграничные регионы России, особенно Калининградская область, глубоко интегрированная в европейскую циклическую динамику, являют собой пример того случая, когда региональный цикл инновационного воспроизводства испытывает на себе и зависимость от внешнего цикла (в том числе как от его выгод и роста, так и от его рецессии и других негативных проявлений), и турбулентную динамику геоэкономических процессов, и «выпадение» отдельных циклических звеньев, для которых критическая

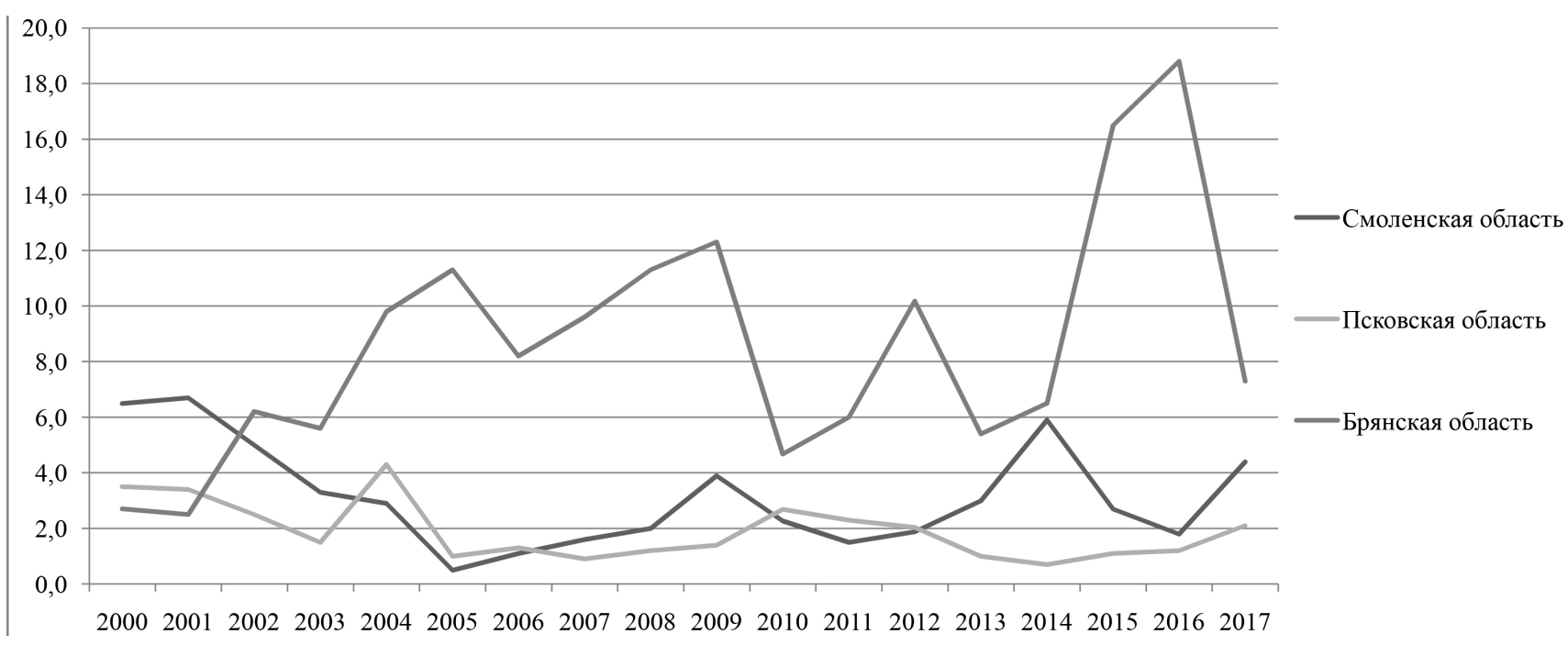

Puc. 7. Динамика доли инновационного продукта в Брянской, Смоленской и Псковской областях, \% (составлено автором на основе: [25]) 
масса формировалась трансграничным пространством в целом (см. Рис. 8).

Для Калининградской области, демонстрировавшей опережающие темпы инновационного роста, резкий спад произошёл ещё в 20082010 , синхронно с общеевропейской рецессией, для Ленинградской области и г. Санкт-Петербурга ощутимы последствия 2014 г. Что интересно, даже в условиях серьёзной (вплоть до критической) рецессии Калининградская область сохраняет свою трёхлетнюю ритмику и за последние годы обнаруживает небольшой рост, 2-3 летний цикл характерен и для Ленинградской области, в то время как г. Санкт-Петербург, будучи непосредственным объектом внимания и интереса федерального центра, а также находясь в наиболее сильной корреляции с общероссийским трендом, повторяет его контур, в том числе воспринимает 4-5-ти летнюю длину волны.

Северные регионы западного порубежья России, так же будучи зависимыми в плане производства инновационного продукта от федерального центра и системы госзаказов, обнаруживают собственную логику развития (см. Рис. 9).

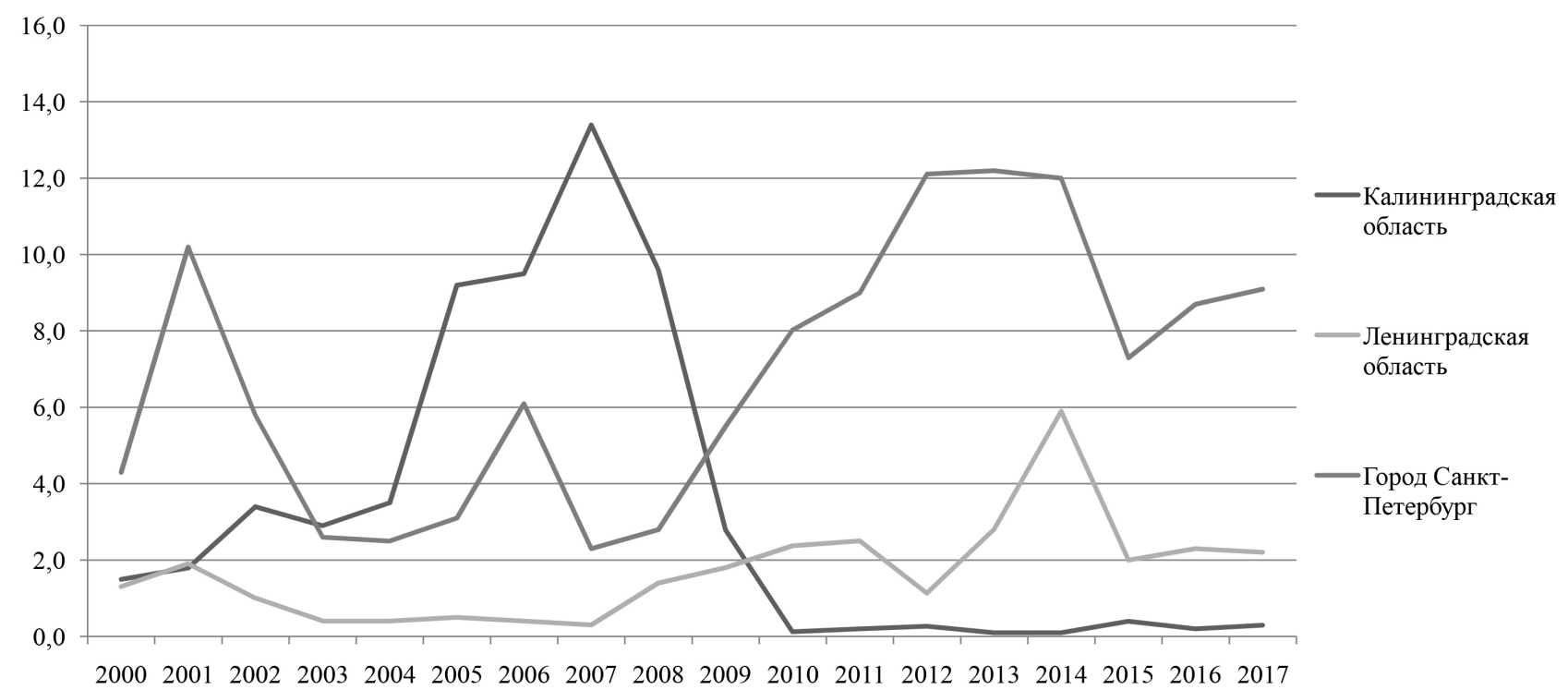

Puc. 8. Динамика доли инновационного продукта в регионах российской Балтики, \% (составлено автором на основе: [25])

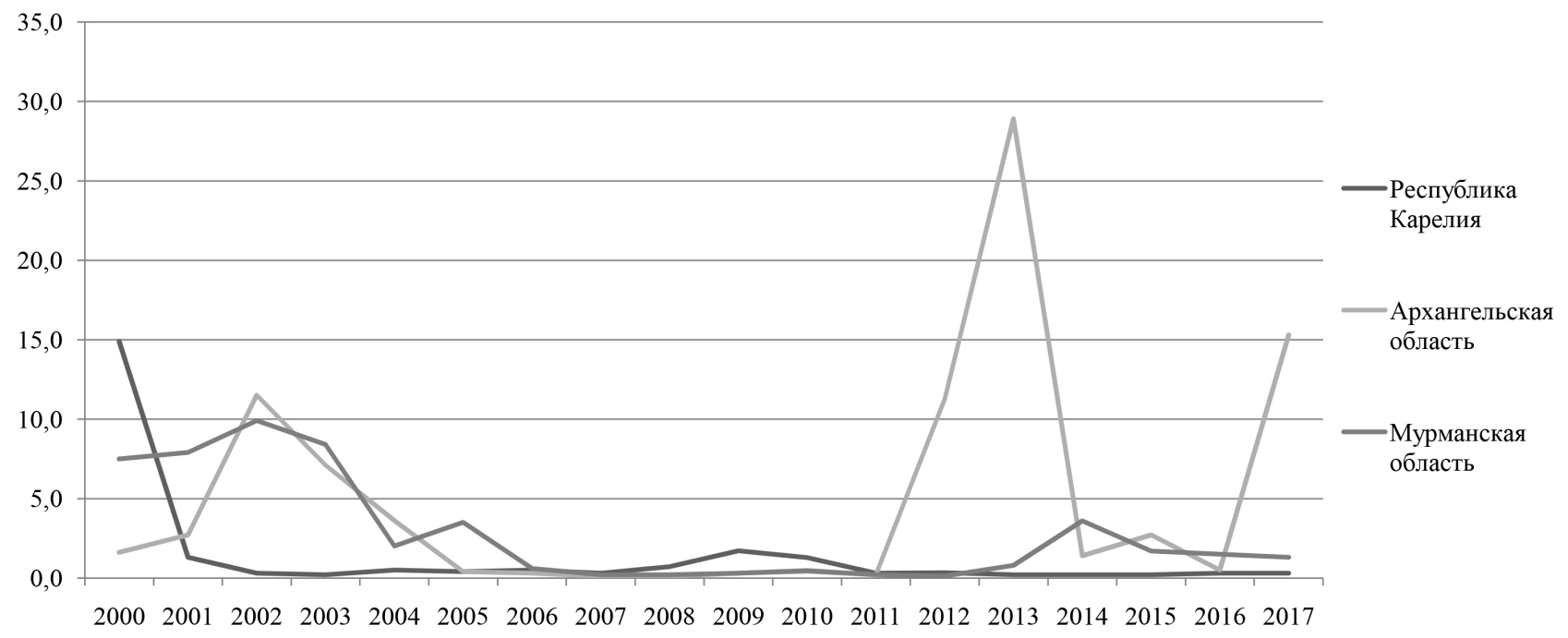

Puc. 9. Динамика доли инновационного продукта в Республике Карелия, Мурманской и Архангельской областях, \% (составлено автором на основе: [25]) 
Отдельные этапы роста, ведомые госпроектами (в особенности в сфере ВПК) в Архангельской области и в меньшей мере - в Мурманской, не способствуют становлению устойчивого и самостоятельного цикла самоорганизации инновационного воспроизводства. Есть вероятность, что такой эффект может спровоцировать повышение объёмов деятельности за последние годы в Архангельской области. Критически низкий уровень инновационной продукции наблюдается в Республике Карелия.

Сопоставляя прослеженную по всем регионам динамику доли инновационного продукта с особенностями кластерообразования, эмпирически выявленными в нашем исследовании [8], можно обнаружить полное соответствие двухлетнего цикла инновационного воспроизводства, свойственного западным приграничным регионам в целом - с установившейся примерно после 2010-2014 гг. и продолжающейся в настоящее время двухлетней ритмикой формирования новых поколений кластеров. В отсутствие в современной российской системе сбора и представления официальных статистических данных по всем параметрам, характеризующим фазы цикла инновационного воспроизводства, данное обстоятельство служит эмпирическим подтверждением тесной взаимосвязи самоорганизации и саморегуляции инновационного сектора региональной экономики (как гарантии инновационной безопасности, способной к самоподдержанию) - с кластерообразующими трендами регионального развития.

Обсуждение и заключение. Представленные в настоящей работе концептуально-теоретические положения, а также краткий экспресс-анализ эмпирического материала призваны скорее задать новое направление в региональной экономической научной мысли, наметить возможные пути и ракурсы изучения мультциклической самоорганизующейся и саморегулятивной логики регионального инновационного воспроизводства, в том числе в условиях внешней зависимости. Представленные в данной статье подходы и заявленные тезисы нуждаются в дальнейшем развитии, в том числе в плане разработки более детального инструментально-методического аппарата импликации к региональной практике с учётом недостатков сложившейся системы официальной российской статистики, не фиксирующей существенную часть показателей, необходимых для решения данной задачи.

Тем не менее, на основании проведённого исследования и разработанной модели можно фиксировать целый ряд положений, важных как в плане теоретического дискурса, так и в плане регионального управления, а именно:

1. Инновационная безопасность региона представляет собой особое состояние региональной социально-экономической системы, при котором за счёт действия самоорганизующихся механизмов осуществляется предотвращение и противодействие действующим и потенциальным угрозам её инновационного воспроизводства.

2. Изучение инновационной безопасности региона должно включать анализ циклических взаимосвязей с основными подсистемами регионального социально-экономического воспроизводства, так как именно от них зависит саморегуляция и в итоге - жизнеспособность инновационной подсистемы региональной экономики и её «иммунитет» по отношению к внешним вызовам.

3. Специфика инновационной безопасности приграничных регионов определяется их активной включённостью в территориальное разделение труда и зависимостью от сопредельных территорий, задающих циклическую ритмику инновационного воспроизводства на уровне макрорегиональных трансграничных образований, а также чувствительностью по отношению к внешней турбулентной динамике и рискам выпадения отдельных фаз воспроизводственного цикла.

4. Саморегуляция и расширение возможностей роста в условиях сложившегося цикла инновационного воспроизводства осуществляется естественным образом, а при отсутствии синхронизации звеньев между собой - нуждаются в специальном внимании к институциональным и механизмам. При этом необходима координация между самими данными механизмами, что означает не просто взаимодействие бизнеса, науки и образования, государства и общества, СМИ при интегрирующей роли экономических кластеров, но и их согласованную, соразмерную, алгоритмически выстроенную и верно распределённую во времени с учётом особенностей регионального цикла совместную последовательность действий.

5. Инновационная безопасность западных приграничных регионов России в текущих ус- 
ловиях является уязвимым компонентом экономической безопасности при недостаточности внутреннего потенциала отдельных регионов и влияния институциональных факторов и дисбалансов организационной среды других. Проведённый обзор позволяет идентифицировать наибольшие вызовы инновационной безопасности в Калининградской и Псковской областях - вследствие нарушения циклической логики воспроизводства, а также в северных регионах вследствие изначального отсутствия сложившегося цикла.

6. Пролонгированный рост в отдельных регионах, способствующий удлинению волны, имеет место тогда, когда в кластеризацию вступают, наряду с основными профильными, прочие сектора регионального хозяйства (в том числе длительное время находившиеся в кризисном состоянии).

7. В целом, рост инновационного производства в западных приграничных регионах (по среднему показателю) стал результатом реакции деловой среды в виде кластерной самоорганиза- ции в секторах импортозамещения, в то время как существенная рецессия в Калининградской области происходила синхронно с распадом трансграничных кластерных структур, а отсутствие сформировавшихся кластеров в северных регионах не способствует мультипликативному эффекту от реализации масштабных государственных инвестиций в инновационное производство. Также следует учитывать, что отмеченный в ряде регионов рост сам по себе ещё не служит гарантией инновационной безопасности. При сопутствующем повышении амплитуды осцилляции подобная динамика может свидетельствовать о разбалансировке цикла и выпадении отдельных его фаз, а в условиях частичного покрытия затрат и рисков инновационной деятельности за счёт государственной поддержки уязвимым звеном для регионов роста выступает рыночная рентабельность инноваций - тот ключевой инициальный компонент, который запускает собственно экономико-инновационный цикЛ.

Исследование выполнено в рамках гранта РФФИ 19-010-01083 «Проблемы инновационной безопасности и механизмы кластерного экономического развития приграничных регионов Европейской части России»

\section{Библиографический список}

1. Базуева Е.В. Социальный цикл как результат трансформации производственной структуры социально-экономической системы // Вестник АГТУ. Серия: Экономика. 2018. №4. С. 27-35.

2. Багаряков А.В. Инновационная безопасность в системе экономической безопасности региона // Экономика региона. 2012. №2. С. 302-305.

3. Буторина О.В., Осипова М.Ю. Информационный цикл как фактор прогрессивного развития инновационных, технологических и производственных процессов на современном этапе // Вестник ПнИПУ. Социально-экономические науки. 2017. №4. С. 221-233.

4. Буторина О.В., Третьякова Е.А. Методика анализа информационно-инновационнотехнологического цикла на уровне региональных экономических систем // Вестник ПгУ. Серия: Экономика. 2019. №2. С. 289-312.

5. Голова И.М., Суховей А.Ф. Формирование инновационной составляющей экономической безопасности региона // Экономика региона. 2017. №4. С. 1251-1263.

6. Горочная B.B., Дружинин А.Г. Индикация экономической безопасности приграничного региона в условиях геоэкономической турбулентности (на примере Ростовской области) // Государственное и муниципальное управление. Ученые записки. 2019. № 1. С. 96-106.

7. Горочная В.В. Информационный метаболизм и динамика инноваций Ростовской агломерации: роль приморского фактора и экономической кластеризации // Вестник Балтийского федерального университета им. И. Канта. Серия: Естественные и медицинские науки. 2019. № 3. С. 20-37.

8. Горочная В.В. Кластерообразование и инновационная безопасность в регионах западного порубежья России: инвентаризация и основные тренды развития // Региональная экономика и управление: электронный научный журнал. 2019. № 3 (59). С. 11.

9. Горочная В.В. Развитие кластерных структур как самоорганизующийся процесс в региональной экономике: на примере Ростовской области. Дисс. ... к.э.н., Ростов-на-Дону, 2014. 291 с. 
10. Горочная В.В. Турбулентность в геоэкономике: методический подход к моделированию воздействия на экономическую динамику порубежного региона // Экономика устойчивого развития. 2018. № 4 (36). С. $136-142$.

11. Елецкий А.Н., Мищенко К.Н. Повышение экспортного потенциала и геоэкономических позиций Ростовской области посредством кластеризации машиностроения // Российский внешнеэкономический вестник. 2016. №5. С. 57-70.

12. Кадышев Е.Н., Смирнов В.В. Инновационная составляющая экономической безопасности региона // Вестник ЧГУ. 2013. №4. С. 328-333.

13. Куклин А.А., Багаряков А.В., Никулина Н.Л. Инновационная безопасность и качество жизни населения региона // Вестник ЮУрГУ. Серия: Экономика и менеджмент. 2013. №4. С. 20-25.

14. Куклин А.А., Багаряков А.В., Никулина Н.Л. Формирование инновационной культуры в аспекте обеспечения экономической безопасности региона // Управленец. 2012. №9-10. С. 30-33.

15. Луценко E.B. Количественные меры возрастания эмерджентности в процессе эволюции систем (в рамках системной теории информации) // Политематический сетевой электронный научный журнал кубанского государственного аграрного университета. Краснодар, Изд-во Кубанского государственного аграрного университета. 2006. № 5(21). С. 1-20.

16. Малышева Г.А. О социально-политических вызовах и рисках цифровизации российского общества // Власть. 2018. №1. С. 40-46.

17. Мардас А.Н., Кадиев И.Г., Пичушкин Р.В. Управленческий цикл государственного регулирования инновационной деятельности в отраслевом комплексе региона // Инновации. 2008. №5. С. 117-120.

18. Медведева Н.А. Обоснование форсированного прогноза сельскохозяйственного производства Европейского Севера РФ на основе циклических закономерностей // Известия СПбГАУ. 2016. №44. С.182-188.

19. Михайлова А.А. Инновационная безопасность региона: проблема формирования инновационной среды Калининградской области // Вестник Балтийского федерального университета им. И. Канта. Серия: Естественные и медицинские науки. 2017. №4. С. 19-38.

20. Михайлова А.А. Оценка инновационной безопасности регионов России // Национальные интересы: приоритеты и безопасность. 2017. №4 (349). С.711-724.

21. Панченко М.И. Обеспечение экономической безопасности Ростовской области посредством инвестирования в инновации // Проблемы экономики и менеджмента. 2016. №10 (62). С. 15-17.

22. Печаткин B.B. Современные угрозы национальной безопасности страны и их нейтрализация на основе повышения эффективности использования инновационного потенциала региона // Национальные интересы: приоритеты и безопасность. 2016. №9 (342). С. 192-204.

23. Приморские зоны России на Балтике: факторы, особенности, перспективы и стратегии трансграничной кластеризации. Под ред. А. Г. Дружинина. М., 2018. 216 с.

24. Проблемы экономической безопасности регионов Западного порубежья России. Монография. Под редакцией Г. М. Федорова. Калининград, 2019. С. 93-107.

25. Росстат. Официальный портал Федеральной службы государственной статистики. Электронный ресурс. URL: https://www.gks.ru/ (даты обращения 15.10.2019-30.11.2019).

26. Сергеев П.В., Колмыкова Т.С., Сергеев В.П. О проблемах и основных условиях инновационного роста экономики регионов // Вестник Курской государственной сельскохозяйственной академии. 2019. №3. С. 138 -145.

27. Соколов В.В. Мониторинг экономической безопасности в системе трансформации статуса старопромышленного города в инновационный // Пространство экономики. 2011. №3-2. С. 144-150.

28. Трансграничное кластерообразование в приморских зонах Европейской части России: факторы, модели, экономические и экистические эффекты. Под ред. А.Г. Дружинина. Ростов-н/Д., 2017. 421 с.

29. Усманова T.X. Управление инновационными проектами для обеспечения экономической безопасности в условиях интеграции экономик в мировое хозяйство // МИР (Модернизация. Инновации. Развитие). 2017. №1 (29). С. 39-50.

30. Хандажапова Л.М., Лубсанова Н.Б. Проблемы обеспечения инновационной безопасности региона // Региональная экономика: теория и практика. 2015. №17 (392). С. 13-21.

31. Druzhinin A., Gorochnaya V. Economic clusterization and complexion: the specificity of the coastal zones of the South of Russia // Journal of Applied Economic Sciences. 2016. T. 11. № 6. pp. 1017-1025.

32. Kitchin J. Cycles and Trends in Economic Factors // Review of Economics and Statistics . - 1923. - Vol. 5, no. 1. - P. 10-16.

33. Porter M. Competitive Advantage of Nations. N.Y.: Free Press, 1990. 896 p. 